\title{
Partograms and Nomograms of Cervical Dilatation in Management of Primigravid Labour
}

\author{
JOHN STUDD
}

British Medical fournal, 1973, 4, 451-455

\begin{abstract}
Summary
Philpott's graphic labour has been modified and used in 15,000 labours; it has been unanimously accepted by the staff. A nomogram has been constructed to show the normal progressive dilatation of the cervix for primigravidae admitted at different stages of cervical dilatation. Retrospective evaluation of the nomogram showed that it can separate normal labour from labour destined to result in an abnormal outcome, such as longer first and second stages, a greater incidence of instrumental delivery, and babies with low Apgar scores.

It is suggested that the use of a stencil representing normal labour progress, together with Philpott's partogram, will be of considerable use, both in specialist and in general-practitioner units.
\end{abstract}

\section{Introduction}

The simple but revolutionary graphic labour records were designed by Philpott in 1971 for application in Central Africa (Philpott, 1972). By the autumn of that year they were in use in Birmingham (Studd and Philpott, 1972), and through the platform of the Blair Bell Research Society the partogram was introduced to obstetricians throughout the country. It is now in use in about half of the teaching centres in the United Kingdom and seems likely to become the standard means of documenting labour.

The initial introduction in Birmingham was not without problems in spite of daily preparatory lectures to nurses and doctors. But as a result of a pilot study in the professorial unit at the Birmingham Maternity Hospital, and use in Dudley Road Hospital (Studd and Duignan, 1972), certain modifications were made to Philpott's original partogram. This has been adopted and used for some 15,000 labours in the past 18 months.

The second feature of Philpott's graphic records was the use of action lines based on the mean cervical dilatation of the slowest $20 \%$ of African primigravidae. In combination with graphic records action lines have been used in central and peripheral hospitals in Rhodesia (Philpott and Castle, 1972 a), which have reported brilliant results attributable to their use (Philpott and Castle, 1972 b).

Obstetricians in the United Kingdom who have enthusiastically used graphic records have been less willing to apply Philpott's action lines to their patients. The suitability for local use has been questioned because of the racial differences in the population and the belief that the action line, being four hours to the right of Philpott's slowest $20 \%$, is probably about four hours later than the optimum time for oxytocic stimulation. A

\footnotetext{
University Department of Obstetrics and Gynaecology, Birmingham Maternity Hospital, Queen Elizabeth Medical Centre, Edgbaston, Birmingham B15 2TG

JOHN STUDD, M.D., M.R.C.o.G., Lecturer (Now Senior Lecturer, University of Nottingham)
}

further objection is that the patient who is admitted in established labour with a dilatation of $5 \mathrm{~cm}$ or more and who subsequently develops secondary arrest will wait too long before the action line indicates her abnormality.

This article aims (1) to report this experience with Philpott's partogram, (2) to define criteria of normal labour in British parturients, and (3) to assess the value of a nomogram of cervical dilatation based on these data in the management of primigravid labour.

\section{Construction of Partogram}

A partogram of a patient with prolonged labour is given in fig. 1 in order to show the alterations which have been made.

Patient Identification.-This is found in the top left of the partogram, the size being appropriate for the use of selfadhesive identification labels.

Special Instructions.-A space for instructions such as "epidural block," "intravenous ergometrine," or "crossmatch blood" is available at the top right of the partogram.

Duration of Partogram.- Since it would be a vain boast to claim that labour never surpassed 12 hours it was decided to have each partogram run for a 24 -hour period, which would allow the completion of virtually all labours.

Fetal Heart Rate.-Rather than use Philpott's fetal heart rate grade it was decided to use the more orthodox fetal heart rate, being plotted every 15 minutes. Though the advantage of making a quality judgement of the fetal heart was recognized the grading system suggested by Philpott was considered to be an oversimplification which, if insisted on, would delay acceptance of the whole principle of graphic records. Bradycardia is annotated by an arrow down to the lowest fetal heart rate recorded and the type of deceleration shown by "I" or "II," (shown fig. 1).

Starting Time of Partogram.-Vaginal examination and assessment of vaginal dilatation are made as soon as the patient is admitted to the delivery suite, unless there is some obstetric contraindication. This is zero time on the partogram, and this definition applies whether the patient is self-admitted in labour from home, admitted from the antenatal ward in early labour, or admitted to the first-stage room for induction of labour. The first recorded observation is made when the patient is admitted to the delivery suite, as it is meaningless to delay the start of the partogram until some arbitrary time when labour is adjudged to be well established or in the acceleration phase.

Events before Zero Time.-Duration of rupture of membranes and duration of labour before the partogram is started are recorded in the two boxes at the left of the partogram.

Descent of Head.-Medical and nursing staff quickly accepted this new assessment of the head level by the amount of head palpable abdominally in "fifths." This assessment of head level was easily achieved, being reproducible among both senior and junior staff. Precise appreciation of head level has banished expressions such as "at the brim," "through the brim," and "engaging" from our obstetric vocabulary. Head level is shown as a large dot on the $0-5$ gradations on the cervicograph. The level of the head assessed by vaginal examination should not be omitted. With each dot of abdominal head level should be information about the station of the leading bony point of the head in relation to the ischial spines and alsoabout the position of the head. 


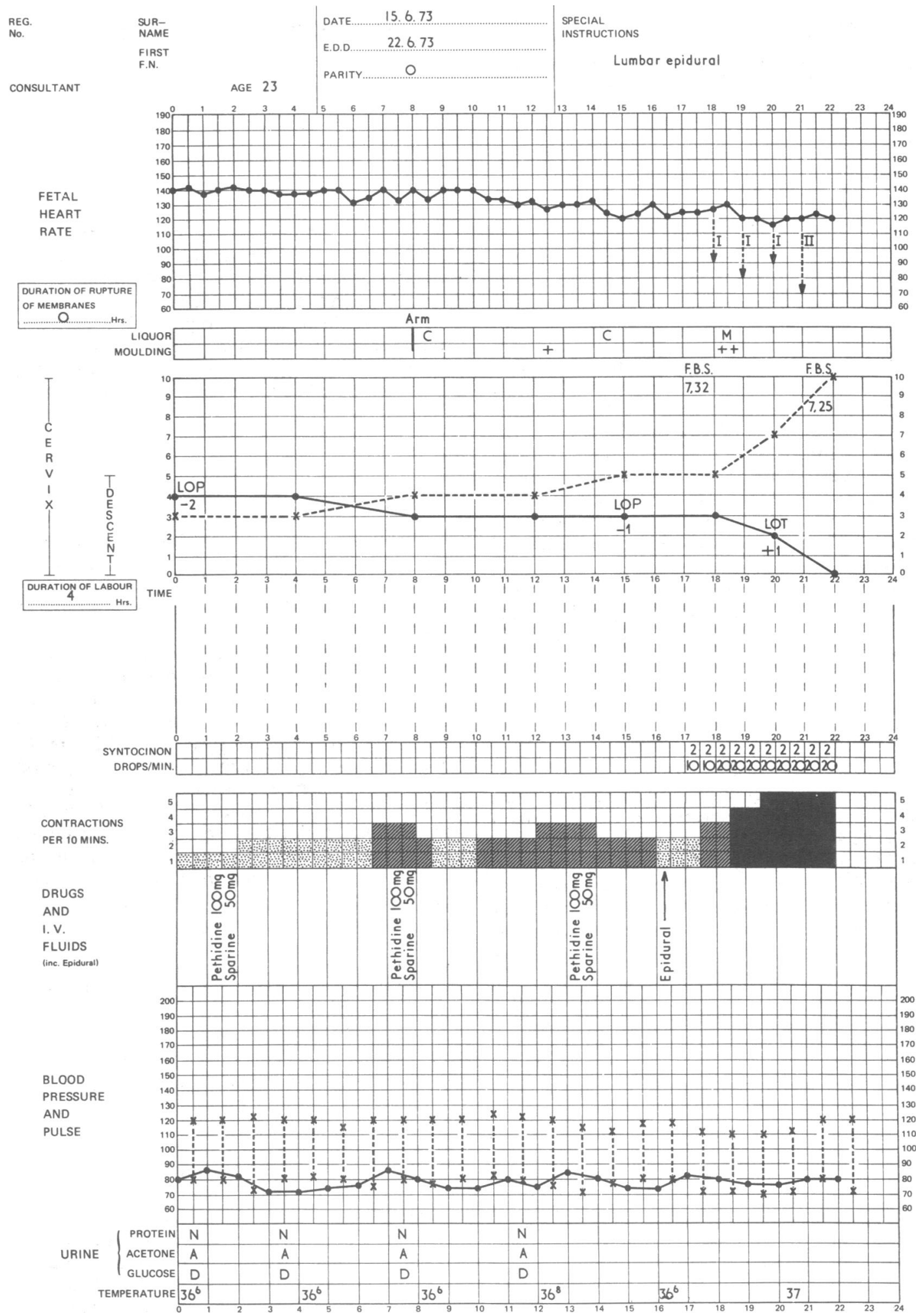

FIG. 1-Partogram showing annotation of events of labour in patient with prolonged labour.

Cervicograph.-As cervical dilatation is the most important indicator of progress of labour, it is proper that the cervicograph should be the most dominant part of the labour charts. This was so in Philpott's original version, but regrettably it has been necessary to expand the space available for fetal heart rate and maternal blood pressure and pulse at the expense of the cervicograph, which now measures 23 by $6.2 \mathrm{~cm}$ to represent 24 hours and $10 \mathrm{~cm}$ dilatation respectively. Vaginal examination should be performed at least four-hourly and a slope of cervical dilatation constructed, starting at zero time and finishing at $10 \mathrm{~cm}$ dilatation.
Oxytocics. - The place for information about oxytocic stimulation has been changed to be adjacent to the cervicograph and details of uterine contractions. Ideally oxytocic dose should be documented as $\mathrm{mU} / \mathrm{min}$, and this can be altered as necessary.

Drugs and Intravenous Fluids. - The space allocated for medication is adequate, but as the time of administration of pethidine or epidural anaesthetic agents is critical the exact time should be entered with the dose of the drug.

Maternal Blood Pressure and Pulse.-The space available for these measurements of maternal condition has been expanded. 


\section{Experiences in use of Partogram}

We have found that documentation of a single labour is all that is required for the medical or nursing attendant to become familiar with the principle of graphic records. We have recorded all labours in this manner since September 1971 and can report unanimous acceptance of the partogram by the staff for the following reasons.

(1) A pictorial display of the events of labour clarifies recording in comparison with the lengthy, written notes of the past. This facilitates the recognition of any omission in annotation. Abnormal labour or inefficient clinical practice is highlighted, ensuring better management of the patient.

(2) In spite of fears to the contrary, graphic records are timesaving. But even if the reverse were true it would still be essential that graphic records be implemented for the sake of efficiency.

(3) They have considerable educational value for staff of all levels but are particularly valuable for the teaching of pupil midwives and medical students. All the interrelated variables of labour can be seen on this single page of paper, with the central cervicograph acting as a dynamic computation of these factors. The "hand-over" of the patient from one doctor to another is now more precise and fluent because one has an "at-a-glance" appreciation of the preceding hours of labour, and the probable time of onset of the second stage can be predicted with accuracy by reference to the slope of the cervicograph.

(4) Very few facts about labour cannot be charted on the partogram. Written comments on the labour or comfort of the patient can be made on the lined space on the reverse of the partogram, but it would defeat the purpose of graphic recording to duplicate information about, for example, vaginal examinations, which should all be documented on the cervicograph.

(5) Graphic records help in preventing prolonged labour because labour which is inert can no longer be camouflaged by pages of written notes of varying legibility. Graphic records also facilitate the use of action lines of the sort described by Philpott and Castle (1972 a) and Studd and Duignan (1972).

\section{Criteria of Normal Labour}

To obviate the racial and geographical difficulties encountered in the use of Philpott's action line it was decided to construct the mean cervical dilatation of normal labour for our population. Details of 4,000 labours in patients of all racial groups were coded and subjected to computer analysis. The parameters of normal labour in a preliminary sample of 176 Caucasian nulliparae and 264 Caucasian multiparae are presented here.

Normal labour was defined as one in which the patient was admitted in labour requiring no induction or oxytocic stimulation, had no lumbar epidural anaesthesia, did not require instrumental or abdominal delivery, and was delivered of a baby weighing more than $2,500 \mathrm{~g}$ in good condition. The data for these normal patients are given in table I, and the cervimetric progress shown retrospectively relating to the time of onset of the second stage is shown in fig. 2. The cervimetric progress in primigravid and multigravid patients for admission dilatations of $0-2,3-4,5-6,7-8$, and $9-10 \mathrm{~cm}$ is shown in figs. 3 and 4 respectively.

TABLE I-Details of Labour in Normal Caucasian Women (see text for Definition)

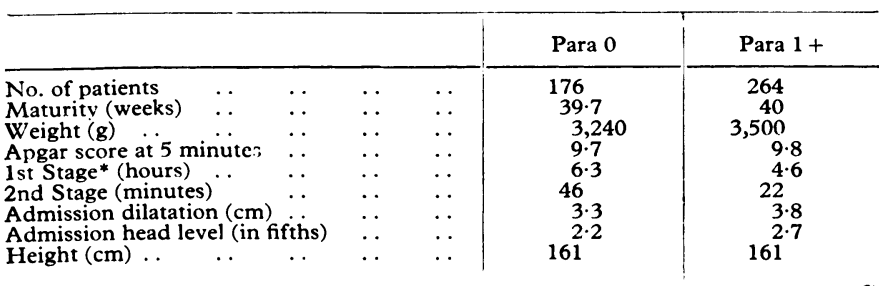

*"1st Stage" refers to time from admission in labour to onset of second stage.

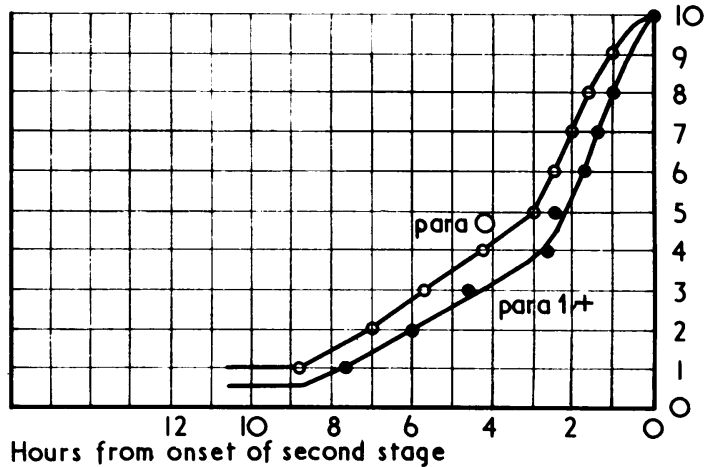

FIG. 2-Cervimetric progress of normal labour in primigravid and multigravid Caucasian parturients with reference to time of onset of second stage.

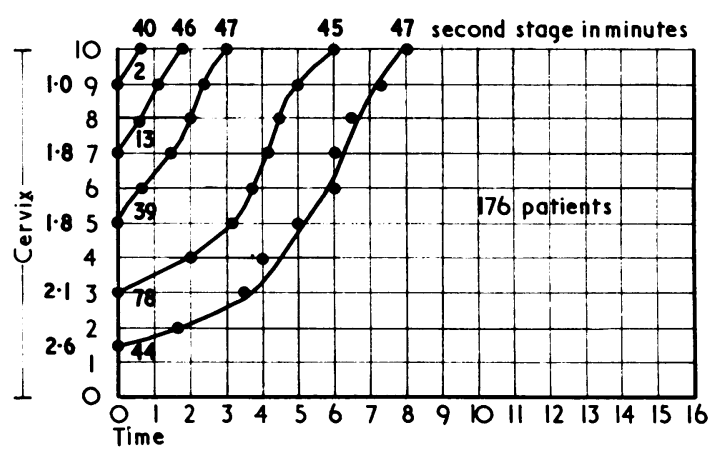

FIG. 3-Cervimetric progress in normal primigravid parturients admitted in labour at cervical dilatations of $0-2,3-4$, $5-6,7-8$, and $9-10 \mathrm{~cm}$. Head level (in fifths) on admission and duration of second stage is also shown.

\section{Nomograms of Cervical Dilatation}

The curve of normal cervical dilatation described by Friedman (1967) is not appropriate for early recognition of patients in prolonged labour because Friedman's curves begin at the socalled onset of labour at zero centimetres and the latent phase is of variable duration. These factors prevent accurate placing of the first assessment of cervical dilatation along the graph.

It would be possible to apply the slope of the mean acceleration phases of 170 normal labours to show the expected progress of labour from a dilatation of $3 \mathrm{~cm}$ (fig. 2). The start of observation of labour, however, is not at some defined time corresponding with the onset of the acceleration phase but is at zero time when the patient is first examined in labour.

It was thought more appropriate to relate expected progress to the admission dilatation (Hendricks et al., 1970), and as progress differed according to the efficiency of labour, and hence the admission dilatation, a modification of fig. 3 has been used as a standard of cervical dilatation of primigravid labour.

The five slopes representing normal labour in patients admitted at five different values of cervical dilatation were drawn on transparent acetate paper and superimposed over the central cervicograph of the partogram. Commercially manufactured acrylic stencils are now being used. On these the 9-10 cm line, considered to be unnecessary, has been removed (fig. 5).

On admission in labour the cervical dilatation is assessed and the stencil used to draw the relevant pencil line of expected progress on the patient's cervicograph, which is then completed in the usual way. This pencil line serves as a nomogram of cervical dilatation. If the patient's cervimetric progress strays two hours to the right of the nomogram labour is adjudged at that stage to be prolonged, requiring acceleration. After vaginal examination to perform amniotomy, if the membranes are still intact, and to exclude malpresentation, the uterine 


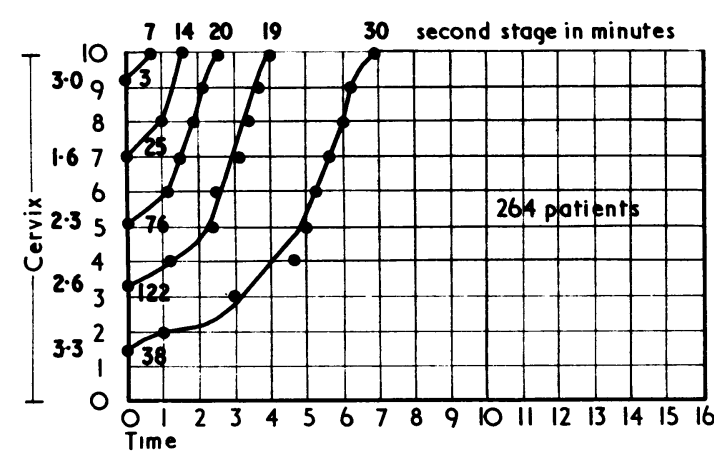

FIG. 4-Cervimetric progress in normal multigravid parturients admitted in labour at cervical dilatations of $0-2,3-4$, $5-6,7-8$, and $9-10 \mathrm{~cm}$. Head level (in fifths) on admission and duration of second stage is also shown.

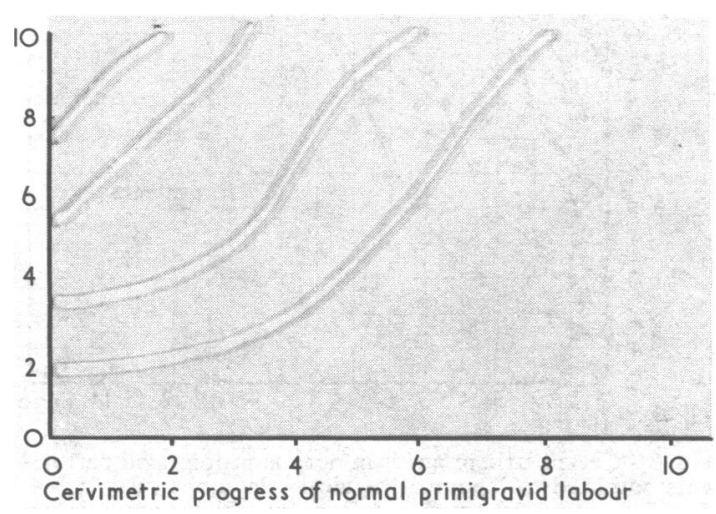

FIG. 5-Acrylic stencil on which progressive cervical dilatation of normal primigravida is used as nomogram of progress for different admission dilatations.

TABLE II-Outcome of 292 Primigravid Labours resulting in Delivery to Left (Group $A$ ) and Right (Group B) of Nomogram. Figures in Parentheses refer to Patients receiving Lumbar Epidural Block

\begin{tabular}{|c|c|c|c|c|c|}
\hline & & & & Group A & Group B \\
\hline $\begin{array}{l}\text { No. of patients } \\
\text { Spontaneous delivery } \\
\text { Low cavity forceps .. } \\
\text { Mid-cavity forceps } \\
\text { Kielland's forceps .. } \\
\text { Ventouse . } \\
\text { Caesarean section } \quad \text {.. }\end{array}$ & $\begin{array}{l}\because \\
\because \\
\cdots \\
\cdots \\
\cdots\end{array}$ & $\begin{array}{l}\cdots \\
\cdots \\
\cdots \\
\cdots \\
\cdots\end{array}$ & $\begin{array}{l}\ldots \\
\cdots \\
\cdots \\
\cdots \\
\cdots\end{array}$ & $\begin{array}{r}164 \\
136(7) \\
7(3) \\
12(6) \\
5(1) \\
4(3) \\
0\end{array}$ & $\begin{array}{l}128 \\
68(13) \\
2(2) \\
33(23) \\
12(7) \\
10(2) \\
3(1)\end{array}$ \\
\hline
\end{tabular}

contractions are stimulated by a small augmenting infusion of oxytocin (Syntocinon). During this period of stimulation the fetal heart must be observed by the best means available, which would ideally be continuous fetal heart rate recording with reference to the intrauterine pressure. Stimulation of labour in this way is continued as long as there is good progress in the absence of fetal distress.

Evaluation of Nomogram.-Before applying the labour stencil throughout the hospital a retrospective study was performed to determine the ability of the nomogram to separate normal labour from labours with an abnormal outcome. A total of 292 consecutive primigravid labours of spontaneous onset occurring from January to March 1972 inclusively were studied because the date from these labours were not used in the construction of the nomogram. Patients in whom labour was induced were not considered. During this period acceleration of labour was practised when considered necessary without there being any standardized policy throughout the hospital.
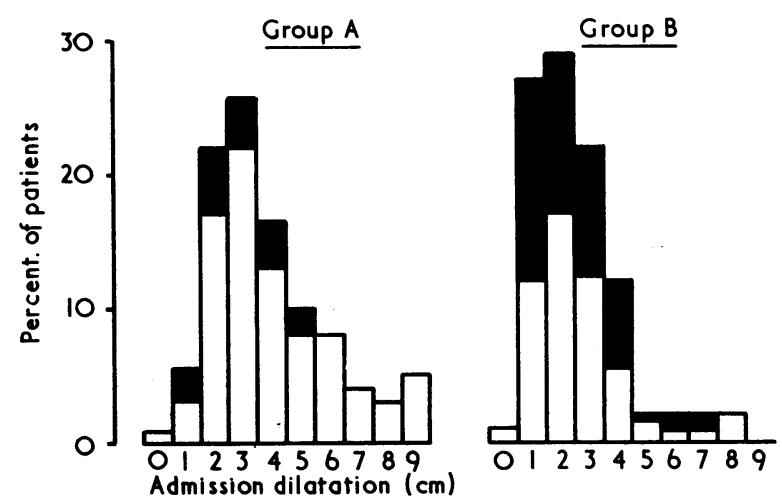

FIc. 6-Percentage of patients in groups $A$ and $B$ admitted at different cervical dilatations. Proportion of patients delivered by instrumentation represented by shaded area at top of each column.

\section{Results}

The outcome of the 164 labours which remained to the left of the nomogram (group A) and the 128 which crossed to the right of the nomogram (group B) is shown in table II, with the number of patients receiving a lumbar epidural block in parentheses. Altogether $83 \%$ of the group A patients were delivered vaginally without instrumentation, compared with only $53 \%$

TABLE III-Details of Labour in 164 Patients who were delivered to Left of Nomogram (Group A) correlated with Dilatation on Admission

\begin{tabular}{|c|c|c|c|c|c|c|c|c|c|c|c|c|c|c|}
\hline \multicolumn{5}{|c|}{ Admission dilatation $(\mathrm{cm})$ : } & 0 & 1 & 2 & 3 & 4 & 5 & 6 & 7 & 8 & 9 \\
\hline 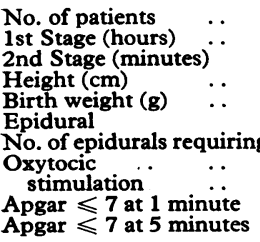 & $\begin{array}{l}\ldots \\
\cdots \\
\ldots \\
\text { ins } \\
\ldots \\
\ldots \\
\cdots\end{array}$ & $\begin{array}{l}\ldots \\
\cdots \\
\cdots \\
\text { nen } \\
\cdots \\
\cdots \\
\cdots\end{array}$ & $\begin{array}{l}\cdots \\
\cdots \\
\cdots \\
\text { on } \\
\cdots \\
\cdots \\
\cdots\end{array}$ & $\begin{array}{l}\because \\
\therefore \\
\cdots \\
\cdots \\
\cdots \\
\cdots \\
\cdots\end{array}$ & $\begin{array}{r}1 \\
8.0 \\
57 \\
165 \\
3,400 \\
1\end{array}$ & $\begin{array}{r}9 \\
6 \cdot 3 \\
43 \\
160 \cdot 1 \\
3,400 \\
5 \\
3 \\
1 \\
1\end{array}$ & $\begin{array}{r}36 \\
5.5 \\
46 \\
159.9 \\
3,300 \\
5 \\
3 \\
2 \\
4\end{array}$ & $\begin{array}{r}42 \\
4.5 \\
46 \\
162.2 \\
3,200 \\
6 \\
4\end{array}$ & $\begin{array}{r}27 \\
3.8 \\
50 \\
162 \cdot 6 \\
3,400 \\
4 \\
3\end{array}$ & $\begin{array}{r}16 \\
2.5 \\
43 \\
158 \\
3,200\end{array}$ & $\begin{array}{r}13 \\
1.9 \\
48 \\
160 \cdot 4 \\
3,400\end{array}$ & $\begin{array}{r}7 \\
1.2 \\
50 \\
161.5 \\
3,100\end{array}$ & $\begin{array}{r}5 \\
1.1 \\
31 \\
163 \\
3,400\end{array}$ & $\begin{array}{r}8 \\
0.55 \\
49 \\
164 \cdot 2 \\
3,200\end{array}$ \\
\hline
\end{tabular}

TABLE IV-Details of Labour in 128 Patients who were delivered to Right of Nomogram (Group B) correlated with Dilatation on Admission

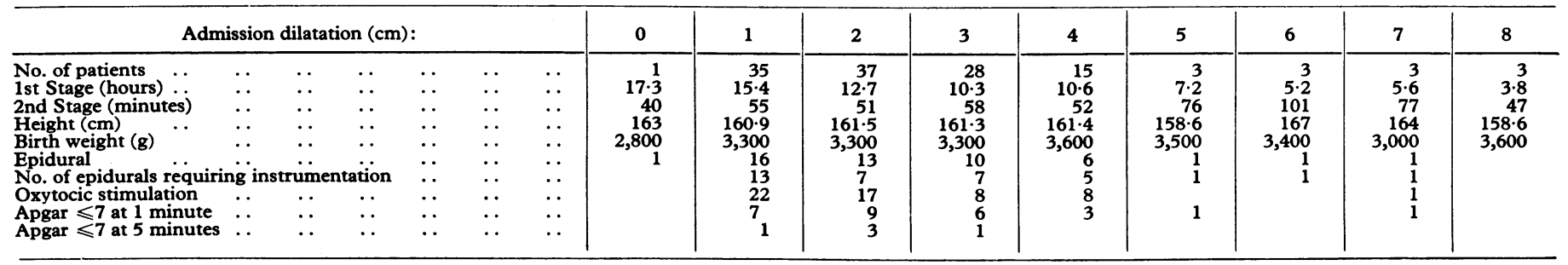


of the group B patients. The admission dilatation of the parturients in both groups and the means of delivery are shown in fig. 6. The height of the patients and details of labour for each admission dilatation, including the length of the first and second stages, birth weight, Apgar score, and incidence of conduction anaesthesia are shown in tables III and IV.

\section{Discussion}

Retrospective evaluation of the nomogram of primigravid labour shows that this simple device may be used to separate normal from abnormal labour. A high proportion of patients in both groups (13 out of 20 in group A, 35 out of 48 in group B) received conduction anaesthesia and required an instrumental delivery. It is not possible to determine whether conduction anaesthesia was a causative factor in the first and second stage prolongation in group B or whether this method of pain relief was applied as part of the proper treatment of stimulated inert labour. Such a cause-and-effect distinction is probable unimportant in evaluation of the nomogram because in either case such patients require intensive monitoring and probably secondstage instrumentation. The effect of epidural anaesthesia on the 4,000 patients in the study group will be reported elsewhere (Duignan and Studd, 1973).

The first stage in group B patients was longer by a factor of 2.2 to 4.8 than the first stage in group A patients. Similarly the mean duration of the second stage was greater in group $B$ in spite of the increased incidence of assisted delivery. There was no significant difference in birth weights or height of patients in groups A and B or in any subgroup. An apgar score of 7 or below at one minute was found in 16 of the 164 babies in group $A$ and 27 of the 128 babies in group B. At five minutes Apgar scores of 7 or below were present in one and five babies respectively.

Augmentation with oxytocin was performed in three patients in group $\mathrm{A}$ and $56(44 \%)$ in group B. The object of acceleration of labour is to reduce the incidence of prolonged labour, fetal distress, second-stage instrumentation, and abdominal delivery for so-called cephalopelvic disproportion or incoordinate uterine action. The suggestion by O'Driscoll et al. (1969) that obstetricians should become active conductors of labour rather than passive observers is well taken, but no benefit can be expected by speeding up normal labour. It might be questioned whether $55 \%$ of the primigravidae recently reported on by O'Driscoll et al. (1973) required acceleration.

The use of nomograms was found to separate the $56 \%$ of primigravid labours in which without conduction anaesthesia delivery is likely to be normal from the patients whose cervicograph passes to the right of the nomogram and who have a high proportion of prolonged labour and abnormal outcome. As nomograms can predict abnormal labour their use will ensure that administration of oxytocics is given to the correct patient at the correct time rather than in a random or belated manner. Their use will also prevent stimulation of labours which are normal and do not require oxytocics.

The proposed time of stimulation is when the patient's cervicograph reaches two hours to the right of her expected progress. If this concept is valid it appears that $25-30 \%$ of primigravid labours of spontaneous onset will require oxytocics.

It is suggested that the use of graphic labour records of the type described by Philpott is a major advance in practical obstetrics. This study shows that the two factors which have a major influence on length of labour and mode of delivery are the patient's cervimetric progress and the presence or absence of a lumbar epidural block. An early warning of prolonged labour may be obtained by reference to a line representing normal cervimetric progress of primigravid labour for a given admission dilatation superimposed upon the cervicograph. This will identify an "at-risk" group of patients requiring acceleration of labour, intensive monitoring, and probable second-stage instrumentation. It is expected that the stencil of normal labour described will find a place in specialist maternity hospitals but that it will be particularly useful for the management of patients under general-practitioner care by giving an indication of the time when referral to specialist care is necessary.

Thanks are due to the medical and midwifery staff of the Birmingham Maternity Hospital for their continued interest and help.

Graphic labour records may be obtained from J. W. Tuckey \& Sons Ltd., Tyseley Industrial Estate, Greet, Birmingham B11 2LJ, and the acrylic labour stencil from M.I.P. Industrial Plastics, Gartmouth Street, Mill Street, Aston, Birmingham.

Requests for reprints should be sent to Mr. John Studd, Nottingham City Hospital, Nottingham.

\section{References}

Duignan, N. M., and Studd, J. W. W. (1973). Unpublished work.

Friedman, E. A. (1967). In Labor, Clinical Evaluation and Management, p. 27. New York, Appleton-Century-Crofts.

Hendricks, C. H., Brenner, W. E., and Kraus, G. (1970). American fournal of Obstetrics and Gynecology, 106, 1065.

O'Driscoll, K., Jackson, R. J. A., and Gallagher, J. T. (1969). British Medical fournal, 2, 477.

O'Driscoll, K., Stronge, J. M., and Minogue, M. (1973). British Medical Fournal, 3, 135.

Philpott, R. H. (1972). British Medical fournal, 4, 163.

Philpott, R. H., and Castle, W. M. (1972 a). Fournal of Obstetrics and Gynaecology of the British Commonwealth, 79, 592 .

cology of the British Commonwealth, 79, 592 .
Philpott, R. H., and Castle, W. M. (1972 b). Fournal of Obstetrics and Gynaecology of the British Commonwealth, 79,599 .
cott

Studd, J. W. W., and Duignan, N. M. (1972). British Medical fournal, 4, 426.

Studd, J. W. W., and Philpott, R. H. (1972). Proceedings of the Royal Society of Medicine, 65, 700 . 